\title{
A Study on the Assessment of Impact of COVID-19 Pandemic on Depression: An Observational Study among the Pregnant Women
}

\author{
Roopa Satyanarayan Basutkar ${ }^{1} \cdot$ Shonitha Sagadevan $^{1}$. Oorvashree Sri Hari ${ }^{1}$. Mohamed Jahangir Sirajudeen ${ }^{1}$. \\ Gopi Ramalingam ${ }^{1} \cdot$ Pavithra Gobinath $^{2} \cdot$ Neha Rajesh $^{3} \cdot$ Ponnusankar Sivasankaran $^{1}$ (1)
}

Received: 27 July 2021 / Accepted: 5 August 2021 / Published online: 1 September 2021

(c) Federation of Obstetric \& Gynecological Societies of India 2021

\begin{abstract}
Background COVID-19 pandemic has affected the pregnant women both physically and mentally. This study is conducted to assess, the impact on COVID-19 pandemic on psychiatric symptoms among pregnancy and to compare them with non-pregnant women.

Methods An observational study was conducted at Govt. Medical College \& Hospital, Ooty (Udhagamandalam). A validated Edinburgh Depression Scale was used to screen the mental health status. Categorical variables were analysed using Chi-square test and continuous variables by independent $t$ test. A Pearson's correlation analysis was performed to check the association of Edinburgh postnatal depression scores with the demographic characteristics. Paired $t$ test was conducted to find the difference in EPDS scores at baseline and study conclusion visit. Regression analysis was conducted to predict the outcome variables.

Results The Edinburgh Depression scores were significantly higher in the pregnant women group, $(12.48 \pm 3.753$ vs. $8.00 \pm 2.436 ; p$ value $=0.001 ; 95 \%$ CI 3.340-5.627), when compared to non-pregnant women $(12.90 \pm 3.731$ vs. $9.20 \pm 2.973$; $p$ value $=0.001 ; 95 \%$ CI 2.480-4.920). The Edinburgh Depression scores at the study conclusion visit was statistically significant, $(11.05 \pm 3.839$ vs. $10.24 \pm 3.872 ; p$ value $=0.008 ; 95 \% \mathrm{CI}-1.40$ to -0.213$)$. Education, income, duration of marriage, body mass index, and suicidal ideation are some of the predictors identified in this study to cause depression among pregnant women. Conclusion The findings of the study indicate a clinically significant increase of depressive symptoms among pregnant women. It is recommended to include routine psychological screenings and interventions during pregnancy.
\end{abstract}

Keywords COVID-19 pandemic $\cdot$ Depression in pregnancy $\cdot$ Edinburgh postnatal depression scale $\cdot$ Non-pregnant women

Roopa S Basutkar, PhD, Assistant Professor, Department of Pharmacy Practice, JSS College of Pharmacy, JSS Academy of Higher Education \& Research, Ooty, The Nilgiris-643001, Tamil Nadu, India; Shonitha S, B.Pharm, Department of Pharmacy Practice, JSS College of Pharmacy, JSS Academy of Higher Education \& Research, Ooty, The Nilgiris-643001, Tamil Nadu, India; Oorvashree S, B.Pharm, Department of Pharmacy Practice, JSS College of Pharmacy, JSS Academy of Higher Education \& Research, Ooty, The Nilgiris-643001, Tamil Nadu, India; Mohammed Jahangir S, B.Pharm, Department of Pharmacy Practice, JSS College of Pharmacy, JSS Academy of Higher Education \& Research, Ooty, The Nilgiris-643001, Tamil Nadu, India; Gopi R, B.Pharm, Department of Pharmacy Practice, JSS College of Pharmacy, JSS Academy of Higher Education \& Research, Ooty, The Nilgiris-643001, Tamil Nadu, India; Pavithra G, Assistant Surgeon, Government Medical College and Hospital Ooty, The Nilgiris-643001, Tamil Nadu, India; Neha R, MSC in Statistics, Guest Faculty, School of Life Sciences, Ooty, The Nilgiris-643001, Tamil Nadu, India; Sivasankaran P, Professor and Head, Department of Pharmacy Practice, JSS College of Pharmacy, JSS Academy of Higher Education \& Research, Ooty, The Nilgiris-643001, Tamil Nadu, India.

Extended author information available on the last page of the article

\section{Introduction}

In December 2019, an outbreak of a novel virus causing pneumonia was reported in the city of Wuhan, China [1]. World Health Organization (WHO) named the disease as Coronavirus Disease 2019 (COVID-19) [2, 3]. On 11March 2020 , it was eventually upgraded to the classification of global pandemic [4].

The pandemic was swiftly advancing globally. The health-care services were affected as the pandemic unfolded. Most of the countries started to impose restrictions and lockdown as a part of infection containment strategies [5].

The impact of social isolation, loneliness along with the distress about the risk of getting infection has affected mental health [6].

According to the preliminary data, women have demonstrated significant psychological impact [7, 8]. Pregnant women are having, the higher risk for severe complications 
because of their suppressed immune system [8]. Pregnant women are more concerned about vertical transmission to their fetus [10-12]. Health-care system had collapsed during the pandemic. Patients were categorized and prioritized based on their health conditions for immediate and delayed access to the hospitals. These uncertainties and changes in the health-care practice had caused depression and anxiety among pregnant women [13]. It is mainly dependent on the conditions and living environment $[14,15]$, especially in the second and third trimesters of pregnancy. Depression among pregnant women can adversely affect their fetus, like pre-term labor and low birth weight [16]. The depressive symptom among the pregnant women is about $26 \%$ to $34.2 \%$ during COVID-19 pandemic [17]. Thus, this study is conducted to assess the impact of COVID-19 pandemic on psychiatric symptoms among pregnant women and to compare them with non-pregnant women using the Edinburgh Postnatal Depression Scale (EPDS).

\section{Materials and Methods}

\section{Study Design and Participants}

The single centered, observational study was conducted at Obstetrics and Gynecology Department, Govt. Medical College \& Hospital, Ooty (Udhagamandalam). The baseline visit of the study participants was in the month of May 2021, and study conclusion visit of the last participant was on 30th of June 2021. The study was carried out on pregnant women with a gestational age of 34-36 weeks (baseline visit) and study conclusion visit at 7 days after delivery, while in the non-pregnant women the baseline visit was at the time of enrollment and study conclusion visit was at 4-5 weeks after the baseline visit. A total number of 120 women were recruited and allotted to their respective groups, pregnant women (60) and non-pregnant women (60).

\section{Inclusion and Exclusion Criteria}

Women of reproducible age 18-45 years at the time of consent were included. Women with chronic diseases, a history of high-risk pregnancy, autoimmune diseases, and who had mental health concerns and on any anti-depressants were excluded from the study.

\section{Data Collection}

A team of research staff visited the hospital daily to screen the subjects. Pregnant and non-pregnant women who met the eligibility criteria were invited to participate in the study. The participants and the caretakers were explained the objectives and procedure of the study. The informed consent was obtained in their native or preferred language (Tamil and English).

The inclusion and exclusion criteria were checked after obtaining the consent. The data were collected in a specially designed data collection form to collect the socio-demographic details, medical and medication history, supplement intake, obstetric details, anthropometric measurements, physical examination, and vital parameters at both visits. The maternal and neonatal outcome details were documented at the study conclusion visit for pregnant women who had given birth. The psychiatric symptoms were assessed by administering the self-administered validated Tamil version of Edinburg Postnatal Depression Scale.

\section{Main Outcome Variable}

- The primary outcome variable observed in this study is EPDS scores. The secondary outcome variables considered were maternal and neonatal complications.

\section{Registration and Ethical Considerations}

Ethics Committee approval was obtained from Institutional Review Board. The study was also registered under Clinical Trial Registry of India (CTRI).

\section{Statistical Analysis}

The sample size was calculated by using G-power 3.1 software. The effect size was calculated as $d=0.28$, level of significance $\alpha=0.05$ and power as $90 \%$. A sample of 120 subjects was obtained after the calculation. Sample size was adjusted for dropout rate of $20 \%$.

Descriptive analysis was performed for demographic characteristics. Categorical variables were expressed as percentages and continuous variables as unadjusted means with standard deviations. As the data were normally distributed data, parametric tests were used to measure the differences in variables among the groups. Chi-square test was used for categorical variables, and independent $t$ test for continuous variables was used. Paired t test was used to compare the difference in EPDS score between the baseline and study conclusion visit. A Pearson's correlation analysis was performed to check the association of EPDS scores with participant's demographic characteristics. Regression analysis was conducted to predict the outcome variable. A $p$ value of $<0.05$ was considered as statistically significant. Variation in EPDS scores due to the confounders was measured using $\mathrm{R}^{2}$ values. Prediction modeling of EPDS scores was done using binary logistic regression. All analysis was conducted using the IBM SPSS statistical software (V.22.0; SPSS Inc, Chicago, Illinois, US). 


\section{Results}

\section{Participant Recruitment Status}

A total of 150 pregnant women and non-pregnant women were screened. A total of 120 participants fulfilled the eligibility criteria. A total of 30 participants were excluded, as illustrated in (Fig. 1).

\section{Demographic Characteristics}

The demographic characteristics of the study participants are listed in (Table 1). The factors like education, depression, and suicidal ideation showed significant difference between the groups, while the other variables were equally distributed. The psychiatric symptoms of depression were higher among the pregnant women ( 86.7 vs. $38.3 ; p$ value $=0.001 ; 95 \%$ CI $0.039-0.243)$ at the baseline visit and at the study conclusion visit ( 86.7 vs. $43.3 ; p$ value $=0.001 ; 95 \%$ CI $0.049-0.297$ ). The ideas of self-harm, i.e., suicidal ideation was more prominent among the pregnant women (33.3 vs. $15.0 ; p$ value $=0.019$; 95\% CI 0.152-0.834).

\section{Physical and Vital Sign Examination}

The results of physical examination and vital signs are listed in (Table 2). The participants in the study had a mean age of $24.83 \pm 3.316$ years. No statistically significant differences were seen in physical examination and vital signs between the groups.

\section{Baseline Obstetrics Parameters}

The details of obstetrics parameters were collected at the baseline visit for both groups. Among the non-pregnant women, three participants were of 19 years and did not have obstetric details. Parameters like duration of marriage and type of delivery were statistically significant, while the other parameters like gravida, live, abortion, type of delivery, episiotomy, and type of labor were not statistically significant.

\section{Effect of COVID-19 Pandemic on Psychiatric Symptoms among Pregnant and Non-Pregnant Women}

Independent sample $t$ test was used to compare the means of EPDS between the groups at the visits. The results of the test are represented in (Table 3). The EPDS scores were higher among the pregnant women at the baseline visit $(12.48 \pm 3.753$ vs. $8.00 \pm 2.436 ; p$ value $=0.001 ; 95 \% \mathrm{CI}$ $3.340-5.627)$ and at study conclusion visit of $(12.90 \pm 3.731$ vs. $9.20 \pm 2.973 ; p$ value $=0.001 ; 95 \%$ CI $2.480-4.920)$.

EPDS scores between both the visits were compared by using paired $t$ test, while COVID-19 pandemic was considered as the intervention, as the number of reported positive cases of COVID-19 was more during the study conclusion visit. The EPDS scores were higher during the study conclusion visit, and the test results were statistically significant $(11.05 \pm 3.839$ vs. $10.24 \pm 3.872 ; p$ value $=0.008$; 95\% CI $-1.404-(-0.213)$, showing that EPDS scores varied between the two visits as mentioned in (Table 4).

Pearson's correlation was performed against EPDS scores and variables like income, Body Mass Index (BMI), and age. The correlation coefficient for age was -0.106 , and $p$ value was statistically insignificant $(p=0.249)$ in baseline visit; similarly, in the study conclusion visit, the correlation oefficient was -0.110 with insignificant $p$ value of 0.0234 . The correlation coefficient for BMI was 0.234 with $p$ value of 0.010 at baseline visit andwas 0.214 with $p$ value of 0.019 at the study conclusion visit. The correlation coefficient of income in baseline visit was 0.210 with $p$ value of 0.021 and this increased to 0.382 with $p$ value of 0.001 in the study conclusion visit.

The strength of association between the age and EPDS was found to be a weak negative correlation at both visits. Statistical significance was not found between age and EPDS scores, while income and BMI, was statistically significant. The strength of association between income and EPDS scores had a weak positive correlation on baseline visit, while on study conclusion visit, a moderate positive correlation was found. BMI and EPDS scores were found to have a weak positive correlation at both the baseline and study conclusion visit.

Multiple linear regression was performed, and it showed that BMI and income correlated best with the EPDS scores. The $r$ value of BMI was 0.234 with $p$ value of 0.016 at baseline visit and $r$ value of 0.214 with $p$ value of 0.035 at study conclusion visit. Similarly, the $r$ value of income was 0.210 and 0.382 with $p$ value of 0.034 and 0.001 at baseline visit and conclusion visit, respectively.

Binary logistics regression was performed between two groups. The logistic regression model was statistically significant, $p=0.001$ at both visits. The model explained $31.7 \%$ (Nagelkerke R2) of the variance in depression and correctly classified $74.2 \%$ of cases at the baseline visit, while $27 \%$ (Nagelkerke R2) of variance in depression and $71.7 \%$ of cases were correctly classified at the study conclusion visit.

Binary logistic regression was performed to find the other predictor variable of depression. The results are listed in (Table 5). Education, income, duration of marriage, BMI, and suicidal ideation were statistically significant, $p<0.05$ aat the study conclusion visit. The model explained $54.5 \%$ (Nagelkerke R2) of variance in depression, and it was correctly classified $79.2 \%$ of cases. 
Fig. 1 Flow chart of screening, allocation, and analysis

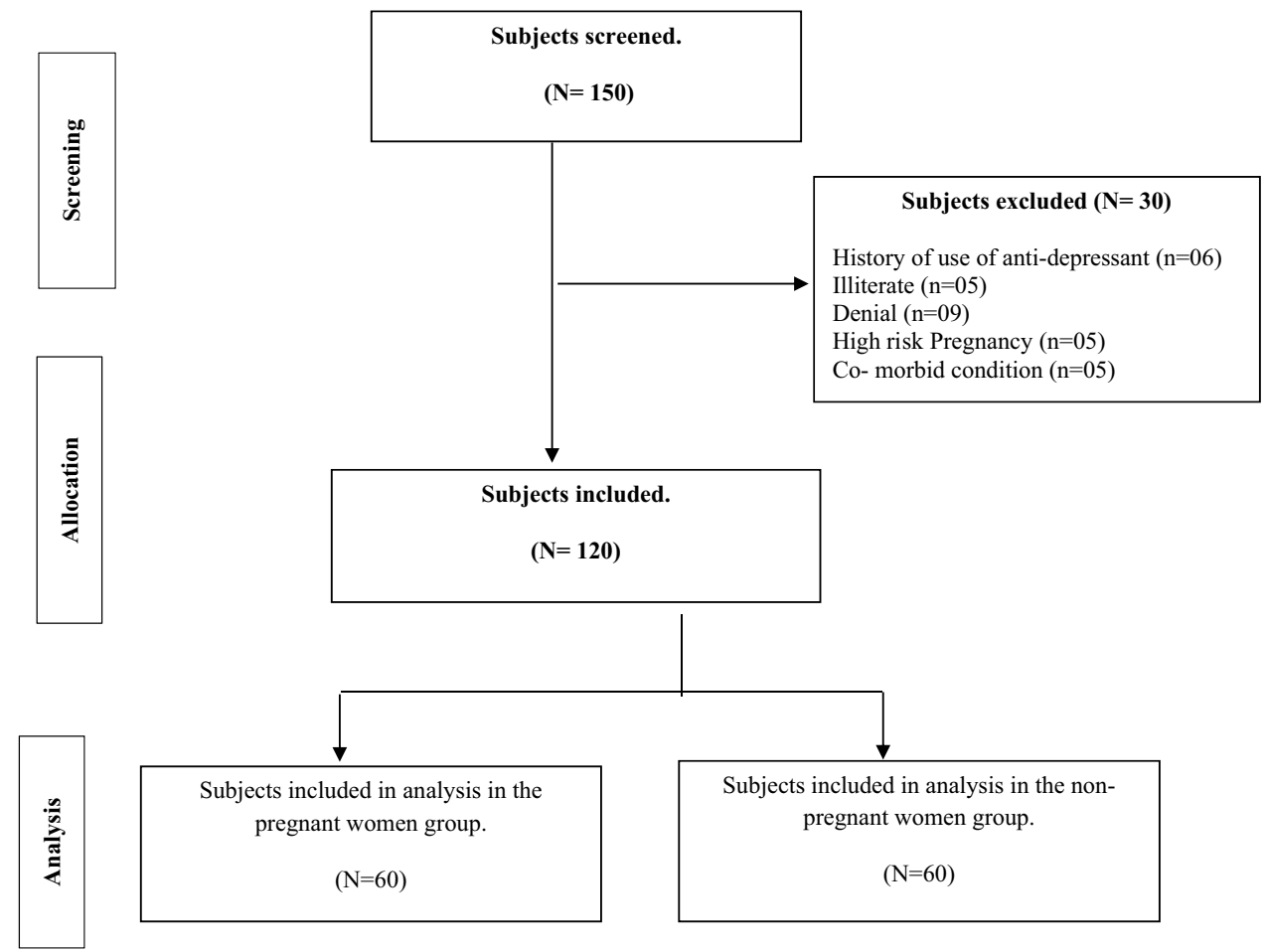

\section{Maternal and Neonatal Outcome}

Maternal and neonatal outcomes of the pregnant women group were analyzed. Mean and SD were computed for the continuous variables, while numbers and percentage were calculated for the categorical variables. About $13.3 \%$ of women were given antenatal steroids because of the risk of preterm delivery. About $13.3 \%$ had stained amniotic fluid, which could have led to the newborn intensive care unit (NICU) admission. About $40 \%$ of pregnant women had Lower (uterine) segment Caesarean section (LSCS). Episiotomy was performed in $51.7 \%$ of pregnant women. And, considering the NICU admission among the neonates, $8.33 \%$ were admitted for level 2 and 3.33\% were admitted for level 3 treatments. Only descriptive statistics were performed for both maternal and neonatal outcome due to the lack of maternal and neonatal data from the non-pregnant women.

\section{Discussion}

COVID-19 pandemic has caused a substantial burden, among the vulnerable population including pregnant women [18]. Studies investigating the impact of COVID-19 pandemic on psychiatric symptoms among pregnant women in comparison with a control group (non-pregnant women) during the pandemic are limited; hence, we conducted this study including both the groups [19]. The baseline visit of the study participants was during the period, when the numbers of registered
COVID-19-positive cases were relatively less and there was no imposition of lockdown. While at the study conclusion visit, it was during the period when the number of cases infected with COVID-19 was high.

The inferential statistics using Pearson's correlation test yielded a moderate positive correlation between income of household and depressive outcomes. The finding of this study was different from the study conducted by $\mathrm{Wu} \mathrm{Y}$ et al [20], in our study the participants, income was substantially constant, and the participants have been at increased risk of getting depressed.

The correlation test also yielded a positive correlation between BMI and depressive outcomes. These findings were dissimilar to the study $\mathrm{Wu} \mathrm{Y}$ et al [21], while in our study, women who were obese had reported the higher depressive scores. Based on the linear regression in our study, the parameters like income of the household and BMI showed to have a significant impact on EDPS scores. These findings of our study were similar to the study conducted in China by Liu X et al [22]. Pandemic has increased the work from home culture, a sedentary lifestyle, there was no option to go for gym, walk and to jog. This is the reason for being overweight. Increased weight during pregnancy is worrisome.

In this study, $85.7 \%$ of pregnant women had their EPDS scores more than 8 , which is a similar finding reported in the study conducted by Liu X et al [20] and Shradha Khatri et al [21]. which is due to worries of vertical transmission, contacting infection while visiting the hospital, and their antenatal and postnatal care visits were reduced [22, 23]. Surprisingly, about 
Table 1 Demographic characteristics of study participants at baseline visit

\begin{tabular}{|c|c|c|c|c|c|c|}
\hline Characteristics & Categories & $\begin{array}{l}\text { Total } \\
(N=120) \\
\text { n }(\%)\end{array}$ & $\begin{array}{l}\text { Non- } \\
\text { pregnant } \\
\text { women } \\
(N=60) \\
\mathrm{n}(\%)\end{array}$ & $\begin{array}{l}(N-60) \\
\mathrm{n}(\%)\end{array}$ & $95 \% \mathrm{CI}$ & $p$ value \\
\hline \multirow[t]{4}{*}{ Education level } & Primary & $30(25.0)$ & $23(38.3)$ & $7.0(11.7)$ & $0.001-0.025$ & 0.001 \\
\hline & Secondary & $48(40.0)$ & $27(45.0)$ & $21(35.0)$ & & \\
\hline & Undergraduate & $23(19.2)$ & $3.0(5.0)$ & $20(33.3)$ & & \\
\hline & Postgraduate & $19(15.8)$ & $7(11.7)$ & $12(20.0)$ & & \\
\hline \multirow[t]{2}{*}{ Occupation } & Employed & $30(25.0)$ & $18(30.0)$ & $12(20.0)$ & $0.7664-3.787$ & 0.206 \\
\hline & Housewife & $90(75.0)$ & $42(70.0)$ & $48(80.0)$ & & \\
\hline \multirow[t]{2}{*}{ Consanguinity } & Present & $28(23.3)$ & $15(25.0)$ & 13(21.7) & $0.5157-2.924$ & 0.666 \\
\hline & Absent & $92(76.7)$ & $45(75.0)$ & $47(78.3)$ & & \\
\hline \multirow[t]{5}{*}{ Consanguinity degree } & First degree & $5.0(4.2)$ & $3.0(5.0)$ & $2.0(3.3)$ & $0.046-0.154$ & 0.179 \\
\hline & Second degree & $11(9.2)$ & $8(13.3)$ & $3.0(5.0)$ & & \\
\hline & Third degree & $5.0(4.2)$ & $3.0(5.0)$ & $2.0(3.3)$ & & \\
\hline & Fourth degree & $7.0(5.8)$ & $1.0(1.7)$ & $6(10.0)$ & & \\
\hline & None & $92(76.7)$ & $45(75.0)$ & $47(78.3)$ & & \\
\hline \multirow[t]{2}{*}{ Diet } & Vegetarian & $23(19.2)$ & $10(16.7)$ & $13(21.7)$ & $0.2786-1.721$ & 0.487 \\
\hline & Non-vegetarian & $97(80.8)$ & $50(83.3)$ & $47(78.3)$ & & \\
\hline \multirow[t]{2}{*}{ Income (INR) } & $>9999$ & $75(62.5)$ & $41(68.3)$ & $34(56.7)$ & $-0.059-0.292$ & 0.190 \\
\hline & $10,000-15,000$ & $45(37.5)$ & 19(31.7) & $26(43.3)$ & & \\
\hline \multirow[t]{2}{*}{ Marital status } & Married & $119(99.2)$ & $59(98.3)$ & $60(100)$ & $0.000-9.000$ & 0.315 \\
\hline & Divorced & $1.0(0.8)$ & $1.0(1.7)$ & 0 & & \\
\hline \multirow[t]{2}{*}{ Suicidal ideation } & Present & $29(24.2)$ & $9.0(15.0)$ & $20(33.3)$ & $0.1524-0.8341$ & 0.019 \\
\hline & Absent & $91(75.8)$ & $51(85.0)$ & $40(66.7)$ & & \\
\hline \multirow[t]{2}{*}{ Depression (At baseline visit) } & Present & $75(62.5)$ & $23(38.3)$ & $52(86.7)$ & $0.03950-0.2436$ & 0.001 \\
\hline & Absent & $45(37.5)$ & $37(61.7)$ & $8.0(13.3)$ & & \\
\hline \multirow[t]{2}{*}{ Depression (study conclusion visit) } & Present & $78(65.0)$ & $26(43.3)$ & $52(86.7)$ & $0.04908-0.2971$ & 0.001 \\
\hline & Absent & $42(35.0)$ & $34(56.7)$ & $8.0(13.3)$ & & \\
\hline \multirow[t]{4}{*}{ EPDS Subscale analysis (At baseline visit) } & Not likely & $42(35.0)$ & 0 & $5.0(8.3)$ & $0.001-0.025$ & 0.001 \\
\hline & Possible & $41(34.2)$ & $37(61.7)$ & $20(33.3)$ & & \\
\hline & Fairly possible & $16(13.3)$ & $21(35.0)$ & $14(23.3)$ & & \\
\hline & Probable depression & $21(17.5)$ & $2.0(3.3)$ & $21(35.0)$ & & \\
\hline \multirow[t]{4}{*}{ EPDS Subscale analysis (At study conclusion visit) } & Not likely & $42(35.0)$ & 0 & $8.0(13.3)$ & $0.001-0.025$ & 0.001 \\
\hline & Possible & $19(15.8)$ & $34(56.7)$ & $12(20.0)$ & & \\
\hline & Fairly possible & $39(32.5)$ & $7.0(11.7)$ & $20(33.3)$ & & \\
\hline & Probable depression & 20(16.7) & $19(31.7)$ & $20(33.3)$ & & \\
\hline
\end{tabular}

$N=$ total number of subjects. $n=$ number of subjects in a given category. $\%=$ n/Number of subjects with available results $\times 100 . \mathrm{SD}=$ standard deviation. INR-Indian Rupees. $p$ value: Pearson's Chi-square or Fisher's exact test (for counts $<5$ ). $p$ value: Comparison of group means using independent-sample $\mathrm{t}$ test

$33.3 \%$ of pregnant women had thoughts of suicidal ideation, which was a significant finding this study. In this study, about $25 \%$ of pregnant women had EPDS score $>13$, which was similar to the finding conducted by Durankus F et al [18] and Shahid A et al [24]. COVID-19 pandemic and lockdown restrictions to travel have shut everyone inside their residences. Fear of getting infected and losing their loved ones due to infection have increased mental pressure among the population. Based on binary logistic regression, education, duration of the marriage, menstrual history, BMI, and suicidal ideation were found to be the predictors of depression and statistically significant. The study participants who were illiterate and completed primary schooling reported higher depressive scores. This may be because of the lack of knowledge about the infection which was similar to the study conducted by Effati-Daryani et al [25]. Women who were married recently showed more psychiatric 
Table 2 Physical and vital sign examination at the base line visit of study participants in both the groups

\begin{tabular}{|c|c|c|c|c|c|}
\hline \multirow[t]{2}{*}{ Characteristics } & $\begin{array}{l}\text { Total participants } \\
(N=120)\end{array}$ & $\begin{array}{l}\text { Pregnant women } \\
(N=60)\end{array}$ & $\begin{array}{l}\text { Non-pregnant women } \\
(N=60)\end{array}$ & $95 \% \mathrm{CI}$ & $p$ value \\
\hline & Mean \pm SD & Mean \pm SD & Mean \pm SD & & \\
\hline Age (Years) & $24.83 \pm 3.316$ & $24.27 \pm 3.379$ & $25.40 \pm 3.179$ & $0.053-2.320$ & 0.061 \\
\hline Height (m) & $153.21 \pm 6.086$ & $152.87 \pm 4.564$ & $153.55 \pm 7.324$ & $-2.890-1.523$ & 0.541 \\
\hline Weight (Kg) & $62.48 \pm 9.226$ & $62.83 \pm 8.559$ & $62.13 \pm 9.907$ & $-2.644-4.050$ & 0.678 \\
\hline BMI $\left(\mathrm{Kg} / \mathrm{m}^{2}\right)$ & $26.70 \pm(4.234)$ & $26.94 \pm(3.890)$ & $26.46 \pm(4.572)$ & $-1.053-2.016$ & 0.535 \\
\hline $\mathrm{SBP}(\mathrm{mmHg})$ & $121.05 \pm 9.441$ & $120.18 \pm 10.344$ & $121.92 \pm 8.442$ & $1.680-5.147$ & 0.317 \\
\hline DBP (mmHg) & $79.54 \pm 9.636$ & $78.75 \pm 9.416$ & $80.33 \pm 9.866$ & $1.903-5.070$ & 0.370 \\
\hline Pulse Rate (BPM) & $79.55 \pm 4.522$ & $79.97 \pm 4.5$ & $79.13 \pm 4.497$ & $2.468-0.802$ & 0.315 \\
\hline Respiratory rate (BPM) & $19.48 \pm 3.138$ & $19.78 \pm 2.675$ & $19.17 \pm 3.538$ & $1.750-0.517$ & 0.284 \\
\hline
\end{tabular}

$N=$ total number of subjects. $\mathrm{SD}=$ standard deviation. $\mathrm{BPM}=$ Beats per minute. $p$ value: Comparison of group means using independent-sample t test

Table 3 Comparison of the means of EPDS results between pregnant and non-pregnant women

\begin{tabular}{llllll}
\hline Characteristics & & $\begin{array}{l}\text { Total }(N=120) \\
\text { Mean } \pm \text { SD }\end{array}$ & $\begin{array}{l}\text { Pregnant women } \\
(N=60) \text { Mean } \pm \text { SD }\end{array}$ & $\begin{array}{l}\text { Non-pregnant women } \\
(N=60) \text { Mean } \pm \text { SD }\end{array}$ & $\begin{array}{c}95 \% \text { CI } \\
\text { EPDS Scores }\end{array}$ \\
& Baseline visit & $10.24 \pm 3.872$ & $12.48 \pm 3.753$ & $8.00 \pm 2.436$ & $3.340-5.627$ \\
& Study conclusion visit & $11.05 \pm 3.839$ & $12.90 \pm 3.731$ & $9.20 \pm 2.973$ & 0.001 \\
\end{tabular}

$N=$ total number of subjects. $\mathrm{SD}=$ standard deviation. $p$ value: Comparison of group means using independent-sample t test

Table 4 Comparison of the EPDS results between the baseline visit and study conclusion visit

Table 5 Binary logistic regression analyses showing independent variables associated with EPDS results as the dependent variable in study population (Study conclusion visit)

\begin{tabular}{lllll}
\hline Characteristics & & $\begin{array}{l}\text { Paired differences between two } \\
\text { groups Total }(N=120) \text { Mean } \pm \text { SD }\end{array}$ & 95\% CI & $p$ value \\
\hline EPDS Scores & Baseline visit & $10.24 \pm 3.872$ & $-1.404-(+0.213)$ & 0.008 \\
& Study conclusion visit & $11.05 \pm 3.839$ & & \\
\hline
\end{tabular}

$N=$ total number of subjects. $\mathrm{SD}=$ standard deviation. $p$ value: Comparison of group means using paired $\mathrm{t}$ test

\begin{tabular}{lrrrrrrr}
\hline Variables & B & S.E & Wald & $p$ value & Exp (B) & \multicolumn{2}{l}{$95 \%$ CI } \\
\cline { 5 - 8 } & & & & & & Lower & Upper \\
\hline Education & & & 9.284 & 0.026 & & & \\
Primary & 1.389 & 0.815 & 2.905 & 0.088 & 4.009 & 0.812 & 19.795 \\
Secondary & -0.188 & 0.765 & 0.061 & 0.806 & 0.828 & 0.185 & 3.707 \\
UG & -1.243 & 1.022 & 1.478 & 0.224 & 0.289 & 0.039 & 2.140 \\
Duration of marriage & & & 6.633 & 0.036 & & & \\
$\quad<1$ year & -2.073 & 0.806 & 6.619 & 0.010 & 0.126 & 0.026 & 0.610 \\
1-4 years & -1.058 & 0.678 & 2.432 & 0.119 & 0.347 & 0.092 & 1.312 \\
Menstrual history & 3.681 & 1.193 & 9.523 & 0.002 & 39.681 & 3.831 & 411.036 \\
BMI & -0.655 & 0.320 & 4.185 & 0.041 & 0.520 & 0.277 & 0.973 \\
Suicidal ideation & -2.228 & 0.896 & 6.189 & 0.013 & 0.108 & 0.019 & 0.623 \\
Constant & -0.765 & 1.475 & 0.269 & 0.604 & 0.465 & & \\
\hline
\end{tabular}


symptoms as they may not be comfortable with the new family and atmosphere.

This study is the first to investigate the mental health status of pregnant women in comparison to non-pregnant women during COVID-19 pandemic in South India. In this study, the odds ratio was measured which is one of the strengths of this study. As the health-care workers, we had opportunity to selfadminister the EPDS scale to all study participants, as most of the similar studies conducted globally had administered the EPDS scale in an online mode and this has reduced the bias in our study. This study has several limitations, as this is an observational study, we were not able to confirm a causal relationship between the COVID-19 pandemic and psychiatric symptoms. Statistical analysis could not be performed for maternal and neonatal complications.

\section{Conclusion}

Recently, COVID-19 has become a global pandemic and many countries are experiencing their second wave of disease. Our study indicates that there was a significant increase in the prevalence of psychiatric symptoms especially during the lockdown period when compared to before lockdown period. Education, income, duration of marriage, BMI, and suicidal ideation are some of the predictors found in the study to cause depression. Psychological health of the pregnant women is of utmost importance under current situation. It is recommended to include routine psychological screening and interventions during pregnancy.

Acknowledgments We thank and acknowledge the support provided by the Government Medical College and Hospital, Ooty. Express our gratitude to all the study participants. We extend our thanks to JSS College of Pharmacy, JSS Academy of Higher Education \& Research, Rocklands, Ooty, The Nilgiris, Tamilnadu, India.

Author Contributions All authors contributed to the study conception and design. Material preparation, data collection, and analysis were performed by [SS], [MJS], [OS], and [GR]. The first draft of the manuscript was written by [SS], [OS], [RSB] [NR], [BV], and [PS], and all authors commented on previous versions of the manuscript. All authors read and approved the final manuscript.

\section{Declarations}

Conflict of interest The authors declare that they have no conflict of interest.

Ethical Approval All procedures undertaken in this study involving human participants were in accordance with the ethical standards of Institutional Review Board, JSS College of Pharmacy, Ooty (JSSCP/ IRB/07/2020-21). The study is registered under CTRI with registration number: CTRI/2021/05/033545.
Informed Consent Informed consent was obtained from all study participants.

\section{References}

1. Graham Carlos W, Dela Cruz CS, Cao B, et al. Novel wuhan (2019-NCoV) coronavirus. Am J Respir Crit Care Med. 2020;201(4):7-8.

2. World Health Organization. Clinical management of severe acute respiratory infection (SARI) when COVID-19 disease is suspected. Interim guidance. Pediatr Med Rodz. 2020;16(1):9-26.

3. Lai C-C, Shih T-P, Ko W-C, et al. Severe acute respiratory syndrome coronavirus 2 (SARS-CoV-2) and coronavirus disease-2019 (COVID-19): the epidemic and the challenges. Int J Antimicrob Agents. 2020;55(3):105-924.

4. Mahase E. China coronavirus: WHO declares international emergency as death toll exceeds 200. BMJ. 2020;10(1):368-408.

5. Chamie J. International migration amid a World in crisis. J Migr Hum Secur. 2020;3:230-5.

6. Pfefferbaum B, North CS. Mental health and the COVID-19 pandemic. N Engl J Med. 2020;383(6):510-2.

7. Wang C, Pan R, Wan X, et al. Immediate psychological responses and associated factors during the initial stage of the 2019 coronavirus disease (COVID-19) epidemic among the general population in China. Int J Environ Res Public Health. 2020;17(5):17-29.

8. Woody CA, Ferrari AJ, Siskind DJ, et al. A systematic review and meta-regression of the prevalence and incidence of perinatal depression. J Affect Disord. 2017;219(5):86-92.

9. Kourtis AP, Read JS, Jamieson DJ. Pregnancy and infection. N Engl J Med. 2014;370(23):2211-8.

10. Berthelot N, Lemieux R, Garon-Bissonnette $\mathrm{J}$, et al. Uptrend in distress and psychiatric symptomatology in pregnant women during the coronavirus disease 2019 pandemic. Acta Obstet Gynecol Scand. 2020;99(7):848-55.

11. Thapa SB, Mainali A, Schwank SE, et al. Maternal mental health in the time of the COVID-19 pandemic. Acta Obstet Gynecol Scand. 2020;99(7):817-8.

12. Kotabagi P, Fortune L, Essien S, et al. Anxiety and depression levels among pregnant women with COVID-19. Acta Obstet Gynecol Scand. 2020;99(7):953-4.

13. Dashraath P, Wong JLJ, Lim MXK, et al. Coronavirus disease 2019 (COVID-19) pandemic and pregnancy. Am J Obstet Gynecol. 2020;222(6):521-31.

14. Rasul S, Bowen A, Muhajarine N. Factors that moderate or mediate pregnancy complications in women with anxiety and depression. J Pregnancy Child Health. 2017;04(1):360-6.

15. Vigod SN, Wilson CA, Howard LM. Depression in pregnancy. BMJ. 2016;24:i1547.

16. Snapper LA, Hart KL, Venkatesh KK, et al. Cohort study of the relationship between individual psychotherapy and pregnancy outcomes. J Affect Disord. 2018;8(1):1-10.

17. Wu Y-T, Liu J, Xu J-J, et al. Neonatal outcome in 29 pregnant women with COVID-19: a retrospective study in Wuhan. China PLoS Med. 2020;17(7):e100-195.

18. Durankus F, Aksu E. Effects of the COVID-19 pandemic on anxiety and depressive symptoms in pregnant women: a preliminary study. J Matern Fetal Neonatal Med. 2020;18(5):1-7.

19. López-Morales H, Del Valle MV, Canet-Juric L, et al. Mental health of pregnant women during the COVID-19 pandemic: A longitudinal study. Psychiatry Res. 2021;295(1):113567. 
20. Liu X, Chen M, Wang Y, et al. Prenatal anxiety and obstetric decisions among pregnant women in Wuhan and Chongqing during the COVID-19 outbreak: a cross-sectional study. BJOG. 2020;127(10):1229-40.

21. Khatri S, Murthy AK, Hashim U, et al. Psychological status of pregnant women during COVID-19 pandemic: a cross-sectional study from Mumbai. J Mar Med Soc. 2020;22:S113-7.

22. Jungari S. Maternal mental health in India during COVID 19. Public Health. 2020;185(6):97-8.

23. Dong $\mathrm{H}, \mathrm{Hu} \mathrm{R}, \mathrm{Lu} \mathrm{C}$, et al. Investigation on the mental health status of pregnant women in China during the pandemic of COVID19. Arch Gynecol Obstet. 2021;303(2):463-9.

24. Shahid A, Javed A, Rehman S, et al. Evaluation of psychological impact, depression, and anxiety among pregnant women during the COVID-19 pandemic in Lahore. Pakistan Int J Gynecol Obstet. 2020;151(3):462-5.

25. Effati-Daryani F, Zarei S, Mohammadi A, et al. Depression, stress, anxiety and their predictors in Iranian pregnant women during the outbreak of COVID-19. BMC Psychol. 2020;8(9):99.

Publisher's Note Springer Nature remains neutral with regard to jurisdictional claims in published maps and institutional affiliations.

\section{About the Author}

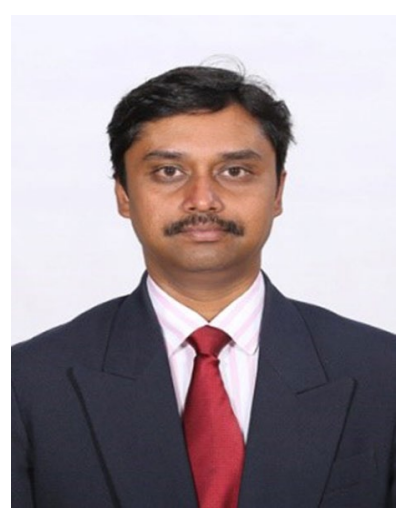

Dr Sivasankaran Ponnusankar is presently working as Professor \& Head at Dept. of Pharmacy Practice, JSS College of Pharmacy, JSS Academy of Higher Education \& Research, Ooty and involved in developing the clinical pharmacy practice and education in India. His area of research interest is community pharmacy practice research; social and administrative pharmacy and health-outcomes research. He has published several research articles (National: 97; International: 27) in his area of research and contributed three book chapters. His research group has received funding from AICTE / DBT for research projects and his students received fellowships from ICMR, DST WoS- B etc. He is a member of various national and international professional associations / organizations.

\section{Authors and Affiliations}

\section{Roopa Satyanarayan Basutkar ${ }^{1}$. Shonitha Sagadevan ${ }^{1}$. Oorvashree Sri Hari ${ }^{1}$. Mohamed Jahangir Sirajudeen ${ }^{1}$. Gopi Ramalingam ${ }^{1} \cdot$ Pavithra Gobinath ${ }^{2} \cdot$ Neha Rajesh $^{3} \cdot$ Ponnusankar Sivasankaran $^{1}$ (1)}

Ponnusankar Sivasankaran

ponnusankarsivas@gmail.com

1 Department of Pharmacy Practice, JSS College of Pharmacy, JSS Academy of Higher Education \& Research,

Ooty, The Nilgiris, Tamil Nadu 643001, India
2 Government Medical College and Hospital, Ooty, The Nilgiris, Tamil Nadu 643001, India

3 Guest Faculty, School of Life Sciences, Ooty, The Nilgiris, Tamil Nadu 643001, India 